\title{
Mídia, ideologia e cocaína (Crack): produzindo "refugo humano"
}

\author{
Moises Romanini - Universidade Federal do Rio Grande do Sul-UFRGS, Porto Alegre/RS, Brasil \\ Adriane Roso - Universidade Federal de Santa Maria - UFSM, Santa Maria/RS, Brasil
}

\begin{abstract}
Resumo
Este artigo origina-se de uma pesquisa cujo objetivo geral foi o de analisar como os usuários de cocaína (crack), inseridos em um Centro de Atenção Psicossocial - Álcool e Drogas (CAPS ad), percebem as formas simbólicas veiculadas na campanha televisiva "Crack, nem pensar". Para colher informações, utilizou-se: (a) observação participante nas reuniões de equipe dos cuidadores e em outras atividades do serviço, registradas em diário de campo e (b) grupos focais, aqui denominados "Rodas de Conversa". Com base na perspectiva teórica da Psicologia Social Crítica, o referencial metodológico adotado foi a Hermenêutica de Profundidade. Apesar dos discursos hegemônicos e da veiculação maciça de formas simbólicas que sustentam mitos em relação às drogas, bem como das inúmeras estratégias ideológicas identificadas nesta pesquisa, nós pudemos observar que os participantes no estudo foram capazes de assumir um ponto de vista crítico sobre as campanhas.

Palavras-chave: Psicologia social; Televisão; Cocaína.
\end{abstract}

Media, ideology and cocaine (crack): producing “disposable lives”

\begin{abstract}
This article stems from a research whose general objective was to analyze how users of cocaine (crack), attending an Alcohol and Drugs Psychosocial Attention Center, perceive the symbolic forms transmitted on the television campaign “Crack nem pensar" (in English, "Crack? No way!"). To gather information, we used: (a) direct observation in meetings of the care providers and in other activities in the service, registered on a field diary, and (b) focus groups, here called "Roundtable Conversations". Based on the theoretical perspective of Critical Social Psychology, the adopted methodological approach was the Depth Hermeneutics. Despite the hegemonic discourses and mass propagation of symbolic forms that sustain myths about drugs, as well as the numerous ideological strategies identified in this research, we could observe that the participants on the study were able to assume a critical point of view of the campaign. Keywords: social psychology; television; crack cocaine.
\end{abstract}

\section{Medios de comunicación, ideología y cocaína (Crack): produciendo “desecho humano”}

\section{Resumen}

Este artículo tuvo como objetivo analizar cómo los usuarios de cocaína (crack), insertados en un Centro de Atención Psicosocial - Alcohol y Drogas (CAPS ad), perciben las formas simbólicas transmitidas en la campaña de televisión "Crack, nem pensar" (en Español: "Crack, de ninguna manera"). Para recopilar las informaciones, utilizamos: (a) la observación participante en las reuniones de equipo de los cuidadores y otras actividades del servicio, registradas en el campo de diario y (b) grupos focales, aquí llamados de "Ruedas de Conversación". Basados en la perspectiva teórica de la Psicología Social Crítica, el enfoque metodológico adoptado fue la Hermenéutica de Profundidad. A pesar de los discursos hegemónicos y la colocación de masivas formas simbólicas que sostienen mitos acerca de las drogas, así como las numerosas estrategias ideológicas identificadas en esta investigación, podemos observar que los participantes del estudio fueron capaces de tener una visión crítica sobre las campañas.

Palabras clave: Psicología social; Televisión; Cocaína.

Esse artigo origina-se da dissertação de mestrado intitulada "Rodas de Conversa sobre a (além da) Campanha 'Cracke, nem pensar': a Saga do 'SuperHomem Moderno' em tempos de crack”, defendida junto ao Programa de Pós-Graduação em Psicologia da Universidade Federal de Santa Maria ${ }^{1}$. O objetivo geral da dissertação foi o de analisar como os usuários de crack, inseridos em um Centro de Atenção Psicossocial - Álcool e Drogas (CAPS ad), percebem as formas simbólicas veiculadas na campanha televisiva "Crack, nem pensar"2.

Dois conceitos foram fundamentais para a reflexão teórica empreendida: a midiação da cultura moderna e a noção de ideologia. A midiação da cultura é concebida como uma característica fundamentalmente constitutiva das sociedades modernas. Consiste no "processo geral através do qual a transmissão das formas simbólicas se tornou sempre mais mediada pelos aparatos técnicos e institucionais das indústrias da mídia" (Thompson, 2007, p. 12). Ela Disponivel em www.scielo.br provoca mudanças na forma como as pessoas se relacionam, no conteúdo e na maneira como as mensagens são transmitidas pela mídia, fazendo com que o conhecimento que nós temos dos fatos que acontecem além do nosso meio social imediato seja derivado da recepção das formas simbólicas (ações e falas, imagens e textos) veiculadas pelos meios de comunicação (Guareschi, 2003; Thompson, 2007).

$\mathrm{O}$ desenvolvimento dos meios de comunicação nas sociedades modernas tornou possível a veiculação maciça de fenômenos ideológicos, transformando-os em fenômenos de massa. Ideologia, nesse sentido, "refere-se às maneiras como o sentido, mobilizado pelas formas simbólicas, serve para estabelecer e sustentar relações de dominação" (Thompson, 2007, p. 79). Relações de dominação são sempre relações de poder assimétricas e injustas, que geram sofrimento psíquico.

Atualmente, a questão do uso do crack entrou na pauta das discussões de saúde e segurança pública, principalmente pelos meios de comunicação. $\mathrm{O}$ uso 
inadequado de substâncias psicoativas tem sido apresentado como uma grave ameaça à saúde de inúmeros brasileiros e relacionado à elevação dos índices de violência e criminalidade em nossa sociedade (Brasil, 2005; Minayo \& Deslandes, 1998; Romani, 2003; Ronzani \& cols., 2009; Vedovatto, 2010). Por esse motivo, a relação entre crack e mídia (ou o crack na mídia) foi o foco de nossas investigações.

Um dos primeiros estudos que focou a mídia e sua relação com o crack mostrou que reportagens publicadas em jornais americanos sobre a "epidemia do crack" eram sensacionalistas, sem embasamento científico e contribuíam para desviar o foco das autoridades sobre outros problemas sociais mais urgentes (Hartman \& Gollub, 1999). Outro estudo norte-americano (Reinarman \& Levine, 1997) indica que a primeira referência à nova forma de cocaína na mídia foi em um artigo publicado em 1984 no Los Angeles Times.

No Brasil, diversos estudos têm mostrado que, nos meios de comunicação, as drogas são consideradas um mal vinculado ao campo jurídico-policial e médicopsiquiátrico e que, invariavelmente, levam os usuários à criminalidade. O discurso antidrogas é apresentado como hegemônico na sociedade atual, tendo como um de seus efeitos a ação repressora e a adoção de uma perspectiva exclusivamente biomédico-curativa (Brasil, 2005; Marinho, 2005; Noto \& cols., 2003; Ronzani \& cols., 2009; Reinarman \& Levine, 2004; Vedovatto, 2010).

Nessa direção, também encontramos a pesquisa realizada pela Agência de Notícias dos Direitos da Infância e do Ministério da Saúde (Brasil, 2005). Constatou-se que tratar de drogas na mídia brasileira significa, quase sempre, tomar como ponto de partida uma relação estreita com a violência urbana, levando o tema a adquirir proporções gigantescas, com reações da mesma ordem, traduzidas em ações cada vez mais repressivas.

Entendemos, dessa maneira, que se faz urgente e necessária a disseminação de debates mais aprofundados sobre o "fenômeno das drogas", para que, mediante uma postura crítica, consigamos desnaturalizar e desmitificar discursos produzidos pelas políticas da "Guerra às Drogas". Por isso, não apenas a análise da recepção é fundamental neste estudo, mas também a preocupação em entender como os usuários de crack percebem essas propagandas e, através da proposta de encontros dialógicos ${ }^{3}$ Jovchelovitch, 2008), evidenciar os saberes dos próprios usuários sobre o tema. A valorização dos saberes dos usuários que podem estar sendo destituídos pelo confronto com os saberes legitimados veiculados na mídia, através da invenção de outras práticas - pode até não criar novas teorias, "mas novos conhecimentos, locais, temporais e políticos” (Hüning \& Guareschi, 2008, p. 14).
$\mathrm{Na}$ análise do material de pesquisa, partimos da noção de capitalismo não apenas como um paradigma econômico da modernidade, mas também como um paradigma cultural, tendo papel fundamental na constituição da modernidade como um projeto sociocultural (Santos, 2010). Ao lado das promessas (não cumpridas) da modernidade - a liberdade, a igualdade e a solidariedade (Santos, 2007) - vai se constituindo uma produção de pessoas, redundantes e indesejáveis (Bauman, 2005). Essa noção vai ao encontro da perspectiva teórica adotada no estudo que é a Psicologia Social Crítica.

Para fins deste artigo, apresentaremos algumas das discussões apresentadas na pesquisa. Após explicitar o método, abordaremos um dos eixos de análise da dissertação: A produção do "refugo humano", subdividido em: Mercado e Consumo; e O Estado Moderno: aparelhos ideológicos e repressivos.

\section{Método}

O local escolhido para a realização da pesquisa foi o CAPS ad Companhia do Recomeço, em virtude da sua especificidade: o serviço foi criado na cidade de Santa Maria (que possui em torno de 280.000 habitantes), no ano de 2009, com intuito de acolher a demanda crescente por tratamento a usuários de crack. Os participantes da pesquisa foram usuários do referido serviço, com idade superior ou inferior a 18 anos, inseridos em um plano terapêutico. Para colher informações, utilizaram-se diferentes estratégias: observação participante (Angrosino, 2009) nas reuniões de equipe e em outras atividades do serviço, registradas em diário de campo (MacRae, 2004; Azevedo \& Carvalho, 2009) e grupos focais (Barbour 2009; Kind, 2004; Roso, 1997), aqui denominados Rodas de Conversa, por se tratar de uma expressão mais familiar aos usuários do que grupo focal.

Após um período de inserção de um dos pesquisadores no local, usuários do serviço foram convidados a participar das rodas de conversa, em caráter voluntário. Foram realizadas três rodas de conversa: a primeira foi composta por sete interlocutores ${ }^{4}$, a segunda por três e a terceira por seis, finalizando com um total de 16 interlocutores (dois do sexo feminino e quatorze do sexo masculino), que aconteceram no primeiro semestre de 2011. Como estímulo ao debate nas rodas de conversa, foram exibidas, duas vezes, as propagandas da Campanha "Crack, nem pensar", veiculadas pelo Grupo Rede Brasil Sul (Grupo RBS, 2009).

Os interlocutores têm idades que variam de 13 a 29 anos, com uma média de 22,75 anos. Se considerarmos que alguns deles fazem uso há algum tempo (um deles refere consumir crack há quase dez anos), a média de idade do início de uso deve ser bem inferior a esta. Conforme as informações contidas nos 
prontuários, apenas um, dos 16 interlocutores, pode ser considerado de classe média-alta. A maioria deles vive em situação de pobreza, alguns dependendo do albergue municipal para ter um local para dormir e se alimentar.

As rodas de conversa compuseram as atividades do serviço, sendo registrados nos prontuários dos usuários os contatos realizados e a participação nos grupos, para que os profissionais do CAPS pudessem acompanhar a realização dessa atividade. A convite dos pesquisadores, dois profissionais do serviço participaram das rodas, um como comediador e outro como observador, de forma voluntária. O convite foi feito à equipe, que ficou responsável por definir quem seriam os profissionais que participariam dos grupos. Desse modo, a realização desta pesquisa não se constituiu em uma simples coleta de dados no local, mas de uma incorporação dos métodos na realidade cotidiana do serviço.

Com base nos pressupostos da Psicologia Social Crítica (Guareschi, 2009), o referencial metodológico adotado foi a hermenêutica de profundidade (Thompson, 2007), que é composta por três fases mutuamente interdependentes e complementares: a análise sócio-histórica, a análise discursiva e a interpretação/reinterpretação. Esse referencial nos possibilita analisar o contexto sóciohistórico e espaço-temporal que cerca o fenômeno pesquisado, bem como empreender análises discursivas e da ideologia como vertente social, o que confere um caráter potencialmente crítico à pesquisa (Thompson, 2007; Veronese \& Guareschi, 2006).

Ao invés de trabalhar separadamente com as três fases distintas da hermenêutica de profundidade, optamos por proceder às análises sócio-histórica e discursiva em bloco único, o que denominamos de análise sociodiscursiva. A análise sócio-histórica tem como objetivo reconstruir as condições sociais e históricas de produção, circulação e recepção das formas simbólicas. A análise discursiva tem como finalidade básica analisar a organização interna das formas simbólicas, com suas características estruturais, seus padrões e relações (Thompson, 2007). Como existem várias maneiras de conduzir a análise discursiva, adotamos a análise temática.

A pesquisa foi aprovada pelo Comitê de Ética em Pesquisa da UFSM (CAEE 0006.0.243.000-11) e segue as exigências e procedimentos da Resolução 196/96 do Conselho Nacional de Saúde, que regulamenta a pesquisa envolvendo seres humanos.

\section{Resultados e Discussão}

Iniciamos a análise sociodiscursiva pela narração de três cenas, registradas no Diário de Campo.

\section{$1^{a}$ Cena}

Assim que ela [a secretária do CAPS] desligou [o telefone], contou-nos a história: era a gerente da escola de idiomas, que fica localizada ao lado do CAPS. Por que ela não foi ali para conversar? (Questionava-me). A reclamação era que, pela manhã, quando a secretária da escola chegou, os usuários estavam ali na frente bebendo [...] e fumando maconha [...]. Ela ainda completou dizendo que no outro dia jogaram objetos pedras e tomates - no pátio deles. Disse também que a secretária tem medo quando chega à escola sozinha e que já perderam alunos por causa das "bagunças" do CAPS.

\section{$2^{a}$ Cena}

Uma situação me chamou muito a atenção [na Oficina Online 7: um participante da oficina estava assistindo ao clipe da música "Eu só quero é ser feliz". Ele estava vidrado na tela e visivelmente emocionado. Cantarolando junto com o clipe, uma lágrima percorreu sua face. [...].

\section{$3^{a}$ Cena}

[...] ele olha para mim e diz: "um dia quero ser igual a tu!". Ele falou sorrindo. Surpreendido pela declaração, questionei: "Como assim?". Ele respondeu: "Eu tenho o sonho de ser um doutor, inteligente... queria ter um consultório só pra mim ou um escritório, pra ficar sentado trabalhando num computador". Ele queria saber o que precisava fazer para alcançar seu sonho. Então conversamos sobre escola, estudos, universidade... e, mais do que isso, sobre esperança. Ele disse que ficou feliz com nossa conversa. E eu também.

Essas cenas não foram escolhidas ao acaso. Manteremos nosso foco, neste momento, apenas na primeira delas. Constatamos que essa cena representa apenas um dos tantos momentos em que a equipe do CAPS teve problemas com a "vizinhança" [sic $]^{5}$. Nesses momentos, a presença dos "indesejáveis" incomoda porque eles "bebem" [sic] e "fumam maconha" enquanto se dirigem ao tratamento e deixam as pessoas com medo em virtude de seus comportamentos ditos "agressivos" [sic].

Nas imediações do serviço encontramos comércios, empresas prestadoras de serviços, escolas, muitas casas e prédios residenciais. Além disso, temos também espaços públicos municipais que, nos intervalos das atividades desenvolvidas no CAPS, são ocupados pelos usuários.

Nas últimas inserções dos pesquisadores no serviço, pudemos acompanhar a necessidade imposta de procurar outro local para o CAPS, pois a proprietária da casa, da qual a Prefeitura Municipal é inquilina, pediu sua desocupação. Salienta-se que o pedido de desocupação não se refere à casa apenas, mas a todos os espaços públicos próximos ao serviço, pedido endossado pelos moradores e empresários locais.

O que pretendemos evidenciar com esta situação é a concepção do sistema capitalista não apenas como um paradigma econômico da modernidade, mas também como um paradigma cultural. Assim como acontece com o lixo que produzimos todos os dias, que 
deve ser transportado para um "lixão" ou aterro sanitário longe da nossa visão, longe do centro da cidade, também pessoas são tratadas como refugos humanos (Bauman, 2005). Essas pessoas, redundantes, "indesejáveis", atrapalham os negócios/comércio local. É preferível que elas permaneçam em outros espaços, afastados do centro, ou, melhor ainda, internados para tratamento. É desse paradigma econômico-cultural da modernidade, o sistema capitalista, que trataremos na próxima seção deste artigo.

\section{Mercado e consumo (alienante): "secando" a carne bumana}

No período do capitalismo desorganizado, o mercado ultrapassou as fronteiras da dimensão econômica e colonizou o Estado e a comunidade, e tem no explosivo crescimento do mercado mundial, na relação salarial precária e na crescente diferenciação dos produtos de consumo suas características fundamentais (Santos, 2010). Contudo, o crescimento do mercado mundial não foi acompanhado por um desenvolvimento social e a maioria dos interlocutores dos grupos realizados expressa esta contradição: eles têm apenas o ensino fundamental incompleto e, no período em que aconteceram os encontros, estavam desempregados.

Numa sociedade de produtores e de consumidores não há espaço para os consumidores falhos, incompletos, imperfeitos. Os consumidores falhos, sem ter um lugar seguro e inquestionável nessa sociedade, só podem ter certeza de uma coisa: excluídos do único jogo possível, não são mais jogadores e, portanto, não são mais necessários, são redundantes (Mance, 1998). Redundância compartilha o espaço semântico de rejeitos, dejetos, restos, lixo com refugo. A história da era moderna tem sido uma longa cadeia de projetos, projetos concebidos através da ideia de que o mundo pode ser sempre transformado.

Criar projetos é sempre um esforço criativo. E o problema reside nisso: o lixo é o ingrediente indispensável do processo criativo. A modernidade, sendo uma condição da produção compulsiva e viciosa de projetos, criou um número excessivo deles, e consigo criou também excesso de lixo, de refugo, refugo humano - pessoas redundantes que não têm espaço no mundo moderno (Bauman, 2005).

As tão difundidas noções de progresso e desenvolvimento econômico, constitutivas do mercado, levam os consumidores a dois tipos de consumo: o alienante e o compulsório (Mance, 1998). No consumo alienante, o consumidor, ao buscar na mercadoria mais do que simples qualidades objetivas, atribui-lhe qualidades virtuais, o que determina sua aquisição e consumo. Nesse processo, a pessoa se torna, ela mesma, uma mercadoria. A fala de um interlocutor expressa este tipo de consumo:
[...] tu usa, tu fuma pra vivê e vive pra fumá, se tu tiver mesmo afundado, sem vontade de sai tu tá, tu tá igual aos cara ali [das propagandas]. Não digo igual, porque, como en falei, eu achei muito... meio forçado demais as imagens, ai sabe, mas o cara tá... o usuário, o usuário tá, praticamente quase tudo igual. [...] Eu já vi gente ai que chegou a bater, a bater até na mãe pra roubar, dentro de casa. $[1-D]^{6}$

O crack é "a droga devastadora, é a droga do milênio" (I-E), é fumado "pra vivê" [sic], para sentir prazer, para sentir o "barato" [sic] da droga que, apesar de passageiro, é muito intenso. Essas são qualidades virtuais atribuídas à droga pelos usuários, após a experiência de consumo da mesma. Quando se "fuma pra vivê", acaba se vivendo "pra fumá" [sic]. Eis o caráter alienante do consumo. $\mathrm{O}$ sujeito passa a ser definido por aquilo que ele consome - por isso, em muitas matérias veiculadas pela mídia, eles são denominados de "crackeiros". Pelo fato de serem reduzidos à identidade de "crackeiros", a percepção que eles têm é a de que "o usuário tá, praticamente quase tudo igual" [sic]. Tornam-se a própria mercadoria quando têm seus atos, como bater na mãe e roubar dentro da própria casa, justificados pelo consumo da droga - é como se dissessem "eu sou o crack".

Além disso, o consumo alienante também se configura pelo valor do produto. Se o consumidor não pode pagar pela mercadoria, tem três soluções imediatas: ou encontra uma maneira de conseguir mais dinheiro - "Quem vai te dar serviço? Que tu é um usuário e tal... Então, tu vai ter que roubar pra sustentar teu vício" (I-A) -, ou negocia a forma de pagamento - "acontece com algumas mulheres, que elas se prostituem pra conseguir crack" (I-R) -, ou, ainda, substitui a mercadoria desejada por outra que ele pode pagar. A última alternativa é destacada por um interlocutor:

Eles tão falando só do cracke, porque é o carro chefe do tráfico de droga hoje em dia é o crack. Antigamente, quando o cara ia comprar cinquenta grama de fumo, o cara pagava trinta pila, hoje tu vai pagar cento e cinquenta, quase não tem, entendeu. Em compensação tu vai... atrás de crack, tu acha baratinho, e o efeito é muito mais forte do que a... mais dinheiro e menos volume, quem nem fala, pra carregar, pra vender, pra tudo. (I-D)

Trata-se, sobretudo, de uma estratégia de mercado. Introduz-se uma nova mercadoria através de uma promoção, seduzindo o consumidor a experimentar a novidade. Nesse ponto, percebemos a passagem do consumo alienante para o consumo compulsório. Enfatiza-se, contudo, que esses dois tipos de consumo são interdependentes e, na maioria das vezes, é muito difícil de identificá-los separadamente. O consumo compulsório se refere, conforme Mance (1998), principalmente aos grupos sociais menos favorecidos economicamente, nos quais essas pessoas 
maximizam seu poder de consumo por meio dos poucos recursos que possuem.

Percebemos também o consumo compulsório nas sucessivas tentativas de buscar a satisfação e de obter o mesmo efeito, ou ainda maior, em relação à droga comumente consumida. Duas contribuições ilustram esse aspecto: "De repente... quem usa maconha, de repente, bah, vem um conhecido, bah, eu tenho um crack aqui, vô experimentar pra mim ver como é" (I-E). E “...faz um pitico? ali, já mistura a maconha com o crack ali... dali uns dias não dá mais o efeito, tu ali já vai só pro crack, a maconha já vai ser descartada" (I-J).

Por fim, arriscamo-nos a pensar num terceiro tipo de consumo: "o consumo às avessas". Essa ideia surge de um comentário realizado sobre a discordância em relação à forma como os usuários são representados mediante as imagens veiculadas nas propagandas: "Mas as pessoas ali não é real. Aquilo ali são pessoas que têm tuberculose, aquela bactéria comedora de gente, né?" (I-A). Após risos e murmúrios, o mesmo interlocutor complementa seu raciocínio: "A bactéria comedora de gente come, que come de dentro pra fora, né meu. Tu pensa que tá bem, uma hora tu vai ver tu já não tem a tua mão" (I-A).

Quando o grupo foi questionado sobre uma possível comparação entre o crack e a "bactéria comedora de gente", um interlocutor pondera que "o crack seca, e não come a carne humana..." (I-AN) e continua afirmando que "na moral ele é assim, o crack ele te droga, o crack te seca de fora pra dentro assim, essa bactéria te come de dentro pra fora. É bem diferente" (I-AN). Parecia haver, no grupo, a preocupação em diferenciar os usuários, reais, daqueles apresentados nas propagandas. Tomando emprestada a dicotomia do dentro e do fora, não nos parece que o crack e a "bactéria comedora de gente" sejam tão diferentes. Tanto o crack quanto a bactéria podem ser considerados algo que era externo e foi introjetado no organismo. Um seca o corpo, o outro come. Em ambos, sentem-se perdas, às vezes irreparáveis.

Nesse sentido, outro interlocutor acredita ser possível comparar a pedra com a bactéria:

Ah, eu acho que sim, porque quanto ao psicológico, quanto à moral da pessoa, quando tu, tu... eu pelo menos quando tava fumando, fui perdendo familia, fui perdendo minha moral, fui perdendo amigos, fui perdendo coisas que eu tinha dentro de casa, fui perdendo muita coisa. Então, eu acho que é uma coisa que vai fazendo tu perder tudo, então acho que não deixa de ser um... (I-L).

Relatos de perdas significativas em razão do consumo de crack foram expressos em todos os grupos. Encontramos na frase acima seis referências ao verbo "perder". Nesse jogo neoliberal de produtores e consumidores, como em qualquer outro jogo, uns ganham e outros perdem. Nesse caso, o consumidor de crack perde, ele "seca". A droga o consome, não é ele que consome a droga. Um "consumo às avessas". Um consumo não somente alienante e compulsório ao mesmo tempo, mas um consumo no qual a alienação é compulsória.

Identificamos, nessa análise sobre o mercado/consumo, ao menos duas estratégias ideológicas de construção de formas simbólicas presentes nos discursos dos nossos interlocutores. A primeira é a padronização, na qual "formas simbólicas são adaptadas a um referencial padrão, que é proposto como um fundamento partilhado e aceitável de troca simbólica" (Thompson, 2007, p. 86). Mediante essa estratégia, os usuários, que são praticamente "tudo igual", passam a ser vistos como "os crackeiros", como um grupo uniforme. Trata-se, portanto, de uma estratégia tipicamente utilizada nos meios de comunicação quando o tema abordado é o uso e/ou usuário de drogas. Essa visão padronizada do grupo de usuários, entretanto, parece estar incorporada no discurso dos interlocutores como algo natural.

A segunda, um pouco em decorrência da primeira, é a diferenciação, que consiste em dar ênfase às distinções e diferenças "entre pessoas e grupos, apoiando as características que os desunem e os impedem de constituir um desafio efetivo às relações existentes" (Thompson, 2007, p. 87). Ao continuarmos mantendo padronizado o grupo dos "crackeiros", por exemplo, mantemo-lo diferente do(s) nosso(s) grupo(s). Ou seja, conseguimos detectar no uso do crack, assim como em outras adicções, um consumo patológico (alienante e/ou compulsório), mas não em nossa forma de consumir. $\mathrm{O}$ outro possui a patologia. E é justamente porque o outro possui a patologia, que nos ameaça e nos amedronta, que se fazem necessárias intervenções dos aparelhos ideológicos e repressivos.

\section{O Estado moderno: aparelhos ideológicos e repressivos}

No período atual, do capitalismo desorganizado (Santos, 2010), observamos a substituição do par ideológico igreja-escola pelo par escola-família (Althusser, 1970/2010). Nos discursos dos interlocutores não há menção alguma sobre escola. Entretanto, o segundo elemento desse par foi discutido em todos os grupos realizados.

A família contemporânea sofre transformações em muitos aspectos, principalmente nas relações intergeracionais e de intimidade, caracterizada pela maior expressão dos afetos e busca de autonomia dos seus membros, visando à construção subjetiva individual. François de Singly (2007) fala da família contemporânea como uma instância caracterizada por três elementos: uma grande dependência em relação ao Estado; uma grande independência em relação aos grupos de parentesco; e uma grande independência de homens e mulheres em relação a esta família.

A transformação da família ocidental tem sido apontada como responsável pela crise da burguesia, 
sobretudo no que diz respeito ao (bom) comportamento de crianças e adolescentes. Aqui é importante destacar o papel da mídia, particularmente da televisão, doméstica e onipresente, que veicula entrevistas com "profissionais da área" com o intuito de legitimar a relação entre a dissolução da família e a delinquência, as drogadições, a desorientação dos jovens, entre outros (Kehl, 2003).

A noção de família dissolvida ou desestruturada traz consigo o modelo de família burguesa oitocentista, e tudo o que foge desse padrão é considerado em desordem, a família em desordem, como denominou Roudinesco (2003). Reside, portanto, nessas formas simbólicas veiculadas pelas mídias, um discurso institucional que responsabiliza a dissolução da família pela situação de degradação social que vivemos, como se a crise social contemporânea não tivesse nenhuma relação com a degradação dos espaços públicos e de políticas sociais destinadas às camadas mais pobres da população.

A primeira reação dos interlocutores à exibição das propagandas é a de concordar com o que está sendo dito: "A realidade tá ali na família. A família sofre junto" (I-AN). O sentimento de culpa pelo sofrimento gerado na família é compartilhado em todos os grupos. Enquanto parece haver certa indiferença em relação aos aspectos direcionados a eles próprios, os interlocutores se dizem "afetados" pelas imagens e texto veiculados nas propagandas no tocante ao sofrimento da família:

A única parte assim que me afetou foi que leva à destruição, que leva a família junto. Isso dai eu vi que aconteceu com a minha. Que todo mundo se mobilizou lá em casa, entendeu? Meus irmãos, nós somos entre cinco irmãos, o pai e a mãe, dois irmãos do casamento antigo do meu pai, dois com a minha mãe, e eu também... então, todo mundo se motivou, todo mundo tá me incentivando. É o que eu tenho conseguido ultimamente. Faz um pouquinho mais de duas semanas que eu não uso nada. Como eu digo, cada dia é uma batalha. (I-E)

O sentimento de culpa pelo sofrimento e pela "codependência" dos familiares se dissolve um pouco a partir da ideia de universalidade do problema: "nenhuma família hoje se escapa mais disso" (I-R), afirma um interlocutor. Nesse ponto da discussão, identificamos a estratégia ideológica da universalização, pela qual "acordos institucionais que servem aos interesses de alguns indivíduos são apresentados como servindo aos interesses de todos" (Thompson, 2007, p. 83). A ideia de que todas as famílias convivem com o problema das drogas parece funcionar, nesse caso, como uma espécie de apaziguador do sentimento de culpa dos usuários, pois eles não são os únicos a causarem sofrimento aos pais.

A culpabilização continua em cena nos grupos, mas, aos poucos, o sentimento que era do usuário, passa a ser descrito como um sentimento dos familiares, que tentam ajudar uma pessoa que é "viciada, e realmente, pelo amor, digamos do pai ou da mãe, seja um parente, ele sofre também junto com a pessoa que usa, eles vão ver e presenciam tudo..." (IA). A imagem do "senhor preocupado" [sic] na segunda propaganda faz com que alguns interlocutores se lembrem dos seus pais: "a imagem da propaganda que veio ali, foi do meu pai esses dias, foi no dia que eu tive um surto mesmo, que ele ficou preocupado mesmo" (I-E). Quando questionado sobre o porquê da preocupação, ele complementa: "Preocupado, né. Bah, será que eu não eduquei bem meu filho pra ele entrar nessa? Ele me falou isso daí [...]. Não fizeram nosso papel de pai mesmo para conseguir educar, porque se perdeu e tal" (I-E).

Nas duas falas citadas acima, observamos o desejo de ter uma família normal (Kehl, 2003), de preferência feliz, sem sofrimentos e que consiga resolver seus problemas no âmbito privado almejado pelo projeto da modernidade (Singly, 2007). Quando isso não ocorre, os pais questionam se não conseguiram exercer o "papel de pai mesmo para conseguir educar" [sic]. Para os que não conseguiram cumprir esse papel, a propaganda, por meio da televisão presente nos lares, pode ter a função de ajudar os pais a "tentarem educar seus filhos" [sic]. A expressão "tentarem educar" nos revela, também, que a tentativa dos pais de colaborar com a construção de uma sociedade sem drogas foi frustrada.

Essa tentativa frustrada e a sensação de não ter cumprido o papel de pai estão associadas à tão veiculada ideia que relaciona a dissolução da família patriarcal e a dissolução dos costumes (Kehl, 2003). Entretanto, percebemos outro movimento, também mediado pelas propagandas, que vai da autoculpabilização dos pais à atribuição de culpa a eles pelos próprios interlocutores. Em primeiro lugar, as propagandas exercem, na concepção dos mesmos, dois efeitos que são paradoxais: assim como elas ajudam os pais a "tentarem educar seus filhos" [sic], elas também, ao causarem um "impacto na sociedade" [sic], colaboram para o aumento do preconceito em relação ao usuário de drogas, gerando consequências negativas no âmbito familiar.

A culpa atribuída à família fica explícita não somente nas críticas direcionadas à maneira de conduzir a situação, após a descoberta da dependência da droga, mas na falha do objetivo primordial de prevenir o uso:

Que nem tem o negócio da família. O cara tem uma familia que nunca teve um drogado na família, certo? Daí o amigo do teu filho é drogado. Ah, porque esse vagabundo tem que morrer. Dai o teu filho entra na droga: meu Deus do céu! Vamos ajudar meu filho... entendeu? Só dói quando... quando pegar... quando a pessoa sentir mesmo, ai ela vai ver... (I-D). 
Ver, olhar, sentir... o familiar não vê que o filho está usando drogas, mas sente depois. A pessoa, enquanto usuária da droga, não vê o sofrimento dos familiares e quando vê, "ele consegue suprir isso no uso" (I-J). "Tipo, tu vê a tua mãe chorando de desespero muitas vezes tu chora junto, mas já pensando em se arrancar pra não ter que vê aquilo e não usá né cara. [...]" (I-D). O sofrimento, causado pela culpa de ter "estragado" [sic] a família, parece vir apenas com a sobriedade. Mas, os familiares, sóbrios, também não conseguem ver o sofrimento do(s) filho(s).

A destruição ou a desestruturação da família (Kehl, 2003; Roudinesco, 2003; Singly, 2007), bem como a atribuição de culpa tanto ao usuário quanto à sua família, decorrente do uso do crack, soam como algo naturalizado nos discursos. Pela naturalização, "um estado de coisas que é uma criação social e histórica pode ser tratado como um acontecimento natural ou como um resultado inevitável de características naturais" (Thompson, 2007, p. 88).

Pela naturalização, a família é considerada culpada pela dissolução dos costumes e dos valores éticos, contudo, a família, sozinha, não vai conseguir transmitir esses valores (Kehl, 2003), pois é necessário que se invista nos espaços públicos desvalorizados, empobrecidos econômica e subjetivamente.

O Estado - que deveria investir nesses espaços -, no caso das drogas ilícitas, tem apresentado sua feição de repressor das atividades condenadas criminalmente, principalmente por meio da polícia (Zaluar, 2008a; 2008b). Essa face repressora determina quem está dentro e quem está fora da lei, quem está a favor e quem está contra a sociedade.

A complicada relação entre esses jovens e o Estado torna-se ainda mais complexa com a presença constante da polícia: "A única paulada que dá em todo mundo é a polícia" (I-AN); "É, no geral é a polícia. O cara fica apavorado com a polícia. Eles podem te pegar com qualquer coisa, mas te pegou com o crack, pronto. Acabou" (I-A). A última frase reflete a criminalização do usuário de crack, independente do crime ser caracterizado como posse e uso ou tráfico. Se eles forem "pegos" [sic] com qualquer outra droga, é possível sair ileso da ação policial: "Se o cara tá com baseado, eles nem dão bola, que é maconha" (I-J). Mas os interlocutores ressaltam que isso ocorre com alguns policiais, pois outros "se pega o cara fumando um baseado já te dá na cara" (I-E).

Percebemos, portanto, que nesses grupos mais vulneráveis à ação policial, os efeitos dessa violenta repressão podem ser desastrosos, por estimularem ainda mais a criminalidade violenta, como fica explícito na fala de um interlocutor:

eu já vi lugar que a policia chega, eles te levam e te jogam pra um campo pra te ajudarem, e lá não, lá eles te cagam de pau. [...]. Agora tem um tal de grupo do exterminio que eles tão matando os usuário, que aí eu acho que é polícia mesmo, entendeu, eles estão matando os usuários. (I-D)

Ao ser questionado sobre o porquê do extermínio, a resposta é direta: "Por quê? Pra acabá. Pra acabá com o usuário..." (I-D). Mas não é para "acabá" [sic] com qualquer usuário, mas com o usuário pobre, esse que perturba o bom convívio social. Zaluar (2008a), mais uma vez nos ajuda a pensar nessa questão:

Jovens de classe média e alta não chegam a ser estigmatizados como problemáticos, anti-sociais ou violentos, apresentando-se muito mais como jovens em busca de diversão ou, quando exageram, jovens que necessitam atendimento por médicos e clínicas particulares. [...]. Jovens pobres, porém, não gozam da mesma compreensão: são presos como traficantes por carregarem consigo dois ou três gramas de maconha ou cocaina, o que ajuda a criar a superpopulação carcerária, além de tornar ilegítimo e injusto o funcionamento do sistema jurídico no País. (p. 9)

A polícia, enquanto representante do aparelho repressivo, atua pela via da violência, prioritariamente, mas também atua pela via da ideologia, sustentando relações históricas de dominação entre "ricos e pobres". Essa atuação fica ainda mais comprometida à medida que a indefinição ou confusão do aparato jurídico acerca da ilegalidade do uso de drogas acaba inflacionando processos de corrupção:

Tem uns que pegam o cara fumando assim, meu, "vamo ver se essa maconha é boa, se não for boa tu vai tomá uma tunda de pau, se for boa tu vai passá". Eles pegam, fumam. E aconteceu comigo já e um camarada do carinha pega e fumar assim e dizer que a maconba era boa e dizer assim "ó quem vai fumar aqui vai ser nós agora" $e$ de eles pegar e fumar, na cara dura. (I-A)

Essa análise traz mais uma vez à tona a estratégia de diferenciação (Thompson, 2007), em uma de suas formas mais violentas e excludentes, pois, ao estabelecer uma diferença radical entre usuário e traficante, entre rico e pobre, entre quem é a favor e quem é contra a sociedade, leva à outra construção ideológica, muito perigosa: o expurgo do outro. Essa estratégia envolve a construção de um inimigo comum, retratado como mau e perigoso e contra o qual os indivíduos são convocados a resistir, ou melhor, combater (Thompson, 2007). Essa estratégia é levada ao extremo no caso citado do extermínio de usuários de crack (pobres), pois leva a pensar que pior que usar drogas é usar crack; e pior que ser usuário é ser pobre!

\section{Considerações finais}

São inúmeros os projetos modernos, e nessa análise nos focamos apenas em alguns: o projeto do mercado globalizado, do consumo desenfreado, dos aparelhos ideológicos e repressivos de Estado (destacando aqui a Família no primeiro caso, e a Polícia no segundo), dos sistemas de desigualdade e opressão. Todos esses projetos operam pela ordem, pela 
eliminação do caos. A busca pela ordem, ao sustentar uma violência matricial (Santos, 2007), exclui tudo o que é considerado lixo, refugo. E, nesse caso, o refugo é humano.

Entendemos que os usuários de crack, nesse contexto, constituem-se e/ou subjetivam-se como "refugos humanos": eles não são bem vindos nos espaços urbanos que ocupam nas redondezas do serviço; eles são motivo de medo e de afastamento de clientes nos estabelecimentos comerciais próximos; e uma atividade desenvolvida dentro do CAPS é significada como bagunça. O problema é que, ao mesmo tempo em que nossos interlocutores têm uma posição crítica em relação à campanha veiculada e às situações de exclusão que vivenciam, os discursos em relação à família, por exemplo, são naturalizados.

As famílias modernas vêm reproduzindo o ideal de família burguesa: nuclear, patriarcal. Quando a família não corresponde aos ideais modernos, ela é considerada desestruturada e, portanto, culpada pelo uso de drogas dos filhos. Esse fato é dado como natural, verdadeiro e inquestionável. Em relação ao Estado, as políticas públicas, como a educação, não tem acessado essa população. A exclusão social que sofrem começa, desde muito cedo, nas escolas, discussão que simplesmente inexiste nas rodas de conversa. Tanto a escola quanto a família podem ser considerados aparelhos ideológicos do Estado, ao passo que a polícia, tão debatida e problematizada em nossos encontros, pode ser pensada como um aparelho repressivo de Estado, pois, por meio da violência, classifica, julga e exclui aqueles que "merecem" ser punidos pelo Estado, fechando o ciclo da produção do "refugo humano".

Precisamos considerar, sobretudo, as limitações do presente estudo. Em primeiro lugar, toda interpretação é parcial e conflitiva e pode, arriscamonos a dizer, ter uma reinterpretação - o que sugere o desenvolvimento de outros estudos relativos ao tema, ampliando o debate e uma compreensão mais profunda desses fenômenos. Como em toda pesquisa, a adoção dos pressupostos teóricos e metodológicos representa, ao mesmo tempo, um aprofundamento e uma limitação. Partindo de um "ponto de vista", aprofundamo-nos na "vista de um ponto", mas não conseguimos, por mais que se tente isso, considerar outras (ou todas as) perspectivas sobre o fenômeno.

À guisa de conclusão, gostaríamos de ressaltar que, apesar dos discursos hegemônicos e da veiculação maciça de formas simbólicas que sustentam mitos em relação às drogas, bem como das inúmeras estratégias ideológicas identificadas nesta pesquisa $(e . g$. naturalização, diferenciação, expurgo do outro, universalização, racionalização, dentre outras), nem tudo está "perdido", pois como disse um dos nossos interlocutores, "nem tudo é sim ou não" [sic], tudo ou nada. Sim, precisamos de mais encontros dialógicos que proponham debates como esses e que, para além do debate, criem processos de singularização na direção de uma construção de espaços coletivos de proposição, implementação e avaliação de políticas públicas.

\section{Referências}

Althusser, L. (1970/2010). Ideologia e aparelhos ideológicos de Estado (notas para uma investigação). Em S. Zizek (Org.). Um mapa da ideologia. (V. Ribeiro, trad.). Rio de Janeiro: Contraponto. (Original publicado em 1970).

Angrosino, M. (2009). Etnografia e observação participante (J. Fonseca, trad.). Porto Alegre: Artmed.

Azevedo, B. M. S. \& Carvalho, S. R. (2009). O Diário de Campo como ferramenta e dispositivo para o ensino, a gestão e a pesquisa. Em S. R. Carvalho, S. Ferigato \& M. E. Barros (Orgs.). Conexões saúde coletiva e políticas de subjetividade (pp. 204-219). São Paulo: Hucitec.

Barbour, R. (2009). Grupos focais (M. F. Duarte, trad.). Porto Alegre: Artmed.

Bauman, Z. (2005). Vidas desperdiçadas (C. A. Medeiros, trad.). Rio de Janeiro: Jorge Zahar.

Brasil. (2005). Mídia e drogas: o perfil do uso e do usuário na imprensa brasileira. Brasília: Agência de Notícias dos Direitos da Infância, Ministério da Saúde.

Grupo RBS. (2009). Painel RBS. Disponível: http://www.cracknempensar.com.br/.

Guareschi, P. A. (2003). Primeira parte - quadro referencial de análise. Em P. A. Guareschi (Org.). Os construtores da informação: meios de comunicaşão, ideologia e ética (pp. 35-92). Petrópolis, RJ: Vozes.

Guareschi, P. A. (2009). Psicologia social crítica como prática de libertação (4 ${ }^{\mathrm{a}}$ ed.rev.ampl.). Porto Alegre: EDIPUCRS.

Hartman, D. M. \& Gollub, A. (1999). The social construction of the crack epidemic in the print media. J Psychoactive Drugs, 31(4), 423-33.

Hüning, S. M. \& Guareschi, N. M. F. (2008). Para inventar o que as teorias não ensinam... Em N. M. F. Guareschi (Coord.), Olhar vidas - a fotografia em uma pesquisa-intervenção. Porto Alegre, RS: Zouk.

Jovchelovitch, S. (2008). Os contextos do saber representaçõs, comunidade e cultura (P. A. Guareschi, trad.). Petrópolis: Vozes.

Kehl, M. R. (2003). Em defesa da família tentacular. Disponível: http://www.mariaritakehl.psc.br.

Kind, L. (2004). Notas para o trabalho com a técnica de grupos focais. Psicologia em Revista, 10(15), 124136.

MacRae, E. (2004). Abordagens qualitativas na compreensão do uso de psicoativos. Em L. A. Tavares, A. R. B. Almeida, E. MacRae \& O. S. Ferreira (Orgs.). Drogas: tempos, lugares e olhares sobre 
seu consumo. Salvador: EDUFBA, CEETAD/UFBA.

Mance, E. (1998). O capitalismo atual e a produção de subjetividades. Disponível: http://www.odialetico.hpg.ig.com.br/filosofia/su bjetividade.htm.

Marinho, M. B. (2005). O demônio nos "paraísos artificiais": considerações sobre as políticas de comunicação para a saúde relacionadas ao consumo de drogas. Interface - Comunic, Saúde, Educação, 9(17), 343-54.

Minayo, M. C. S. \& Deslandes, S. F. (1998). A complexidade das relações entre drogas, álcool e violência. Cadernos de Saúde Pública, 14 (1), 35-42.

Noto, A. R., Baptista, M. C., Faria, S. T., Nappo, S. A., Galduróz, J. C. F. \& Carlini, E. A. (2003). Drogas e saúde na imprensa brasileira: uma análise de artigos publicados em jornais e revistas. Cad. Saúde Pública, 19(1), 69-79.

Reinarman, C. \& Levine, H. G. (1997). The crack attack - politics and media in the crack scare. Em C. Reinerman \& H. G. Levine (eds.). Crack in america: demon drugs and social justice (pp. 18-51). Berkeley: University of California Press.

Reinarman, C., \& Levine, H. G. (2004). Crack in the rearview mirror: desconstruting drug war mythology. Social Justice, 31(1-2), 182- 199.

Romani, O. (2003). Informação sobre drogas: ações, valores e orientações. Em M. Baptista, M. S. Cruz \& R. Matias (Orgs.). Drogas e pós-modernidade - faces de um tema proscrito (2 ${ }^{\circ}$ vol., pp. 33-42). Rio de Janeiro: EdUERJ.

Ronzani, T. M., Fernandes, A. G. B., Gebara, C. F. de P., Oliveira, S. A., Scoralick, N. N. \& Lourenço, L. M. (2009). Mídia e drogas: análise documental da mídia escrita brasileira sobre o tema entre 1999 e 2003. Ciência \& Saúde Coletiva, 14(5), 1751-1762.

Roso, A. (1997). Grupos Focais em Psicologia Social: da teoria à prática. Psico, Porto Alegre, 28(2), 155169.

Roudinesco, E. (2003). A família em desordem (A. Telles, trad.). Rio de Janeiro: Zahar.
Santos, B. de S. (2007). Renovar a teoria crítica e reinventar a emancipação social (M. Benedito, trad.). São Paulo: Boitempo.

Santos, B. de S. (2010). Pela mão de Alice: o social e o político na pós-modernidade (13 ${ }^{\mathrm{a}}$ ed.). São Paulo: Cortez.

Schmidt, M. L. S. (2008). Pesquisa participante e formação ética do pesquisador na área da saúde. Ciência \&o Saúde Coletiva, 13(2), 391-398.

Singly, F. de. (2007). Sociologia da família contemporânea (C. E. Peixoto, trad.). Rio de Janeiro: Editora FGV.

Thompson, J. B. (2007). Ideologia e cultura moderna - teoria social crítica na era dos meios de comunicação de massa $\left(7^{\mathrm{a}}\right.$ ed., Grupo de Estudos sobre Ideologia, Comunicação e Representações Sociais PPGP/PUCRS, trad.). Petrópolis: Vozes.

Vedovatto, S. M. A. (2010). Contrapondo o discurso midiático sobre drogas - nem tão feios, nem tão sujos, nem tão malvados: pessoas de bem também usam drogas! Em L. M. B. Santos (Org.). Outras palavras sobre o cuidado de pessoas que usam drogas (pp. 159-166). Porto Alegre: Ideograf; Conselho Regional de Psicologia do Rio Grande do Sul.

Veronese, M. V., \& Guareschi, P, A. (2006). Hermenêutica de profundidade na pesquisa social. Ciências Sociais Unisinos, 42(2), 85-93.

Zaluar, A. (2008a). Introdução: drogas e cidadania. Em Alba Zaluar (Org.), Drogas e Cidadania: repressão ou redução de riscos (pp.7-22). São Paulo: Brasiliense.

Zaluar, A. (2008b). A criminalização das drogas e o reencantamento do mal. Em Alba Zaluar (Org.), Drogas e cidadania: repressão ou redução de riscos (pp.97-128). São Paulo: Brasiliense.

Recebido em 20/06/2012

Reformulado em 18/03/2013

Aprovado em 14/05/2013 
Nota dos autores:

Apoio

Coordenação de Aperfeiçoamento de Pessoal de Nível Superior - CAPES e ao Programa REUNI, através da concessão de uma Bolsa de Mestrado

Agradecimentos

Aos colaboradores desta pesquisa, Gilson Mafacioli da Silva, Thatiane Veiga Siqueira e Fernanda dos Santos de Macedo

Sobre os autores:

Moises Romanini é psicólogo, mestre em Psicologia (UFSM), doutorando do Programa de PósGraduação em Psicologia Social e Institucional da UFRGS, membro dos Grupos de Pesquisa "Saúde, Minorias Sociais e Comunicação" e "Ideologia, Comunicação e Representações Sociais" e Bolsista CAPES.

Adriane Roso é psicóloga, doutora em Psicologia (PUCRS), especialista em Saúde Pública e em Gestão em Saúde (UFRGS), docente do Curso de Graduação e do Programa de Pós-Graduação em Psicologia da Universidade Federal de Santa Maria, líder do Grupo de Pesquisa "Saúde, Minorias Sociais e Comunicação".

Contato com os autores:

Rua Mal. Floriano Peixoto, 1750, $3^{\circ}$ Andar - Sala 321, CEP 97015-372, Santa Maria/RS- Brasil.

Email: moisesromanini@yahoo.com.br; adrianeroso@gmail.com

\section{Notas}

${ }^{1}$ Essa pesquisa se insere em um projeto maior intitulado "Encontros Dialógicos em um CAPS ad: usuários como interlocutores no debate sobre a campanha "Crack Nem Pensar"', ancorado no Grupo de Pesquisa "Saúde, Minorias Sociais e Comunicação".

2 As propagandas estão disponíveis em: www.cracknempensar.com.br; http://www.youtube.com/watch?v=R-r0UNMsG3E e http:/ /www.youtube.com/watch?v=hiTUvI7Kpcc\&feature=related.

${ }^{3}$ Por Encontros Dialógicos entendemos a possibilidade e a vontade de produzir espaços públicos de diálogo norteado pelas perguntas: quem somos, o que sabemos e o que desejamos, bem como a negativa dessas questões: quem não somos, o que não sabemos e o que não desejamos.

${ }^{5}$ Os participantes desta pesquisa foram denominados de interlocutores, de modo a qualificá-los como "parceiros intelectuais dos pesquisadores na compreensão de fenômenos e na elaboração do conhecimento" (Schmidt, 2008, p. 394).

${ }^{5}$ Usaremos a sigla [sic] para designar "segundo informações colhidas". Referem-se às falas dos interlocutores e serão destacadas com aspas.

6 A letra "I" significa interlocutor; seguida sempre da primeira letra do nome da pessoa autora da fala. Mantivemos as falas no original, ou seja, sem correções gramaticais/ortográficas.

${ }^{7}$ Pitico é um cigarro feito com farelos da pedra de crack misturados à maconha. 